\title{
TRIBUTAÇÃO NO RESULTADO DOS INVESTIMENTOS E DAS APLICAÇÕES NO MERCADO FINANCEIRO NACIONAL
}

\author{
Ângela Bilk, Francieli Mara Heinz Neves, Alyne Cecilia Serpa Ganz, Micheli Aparecida Lunardi \\ Instituição afiliada: Universidade Regional de Blumenau - FURB \\ Instituiçã afiliada: Universitário para o Desenvolvimento do Alto Vale do Itajaí - UNIDAVI
}

angelabilk07egmail.com

\section{Resumo}

Esta pesquisa teve por objetivo principal analisar o impacto da tributação no resultado da rentabilidade dos principais investimentos e aplicações financeiras oferecidos no mercado financeiro nacional. Para isso elaborou-se uma pesquisa descritiva, documental e quantitativa.A população é composta pelos principais tipos de investimento demostrados na Folha de São Paulo. A amostra do estudo foi composta de forma aleatória. O período a ser analisado, constituiu o ano de 2014 a 2015. Para o estudo foram utilizadas as aplicações financeiras disponíveis no mercado financeiro capaz de ser rentável e resgatável em curto prazo, considerando o valor inicial de $\mathrm{R} \$ 100.000,00$. Para a análise dos dados, aplicou-se a técnica da estatística descritiva. Os resultados apontaram que os rendimentos mais significativos foram o dólar, o ouro e o NTN-B. Mas, que o risco alto, médio e baixo, respectivamente, precisa ser avaliado além dos rendimentos. A tributação do IR e das taxas administrativas reduziu os tipos de investimentos recomendados de 12 para 6. Salientando que por seu alto risco o dólar deixa de ser uma opção viável para o valor e período considerados. Apesar do alto valor do imposto e risco médio, o ouro alcançou a mais alta rentabilidade e liquidez e prevaleceu como investimento mais indicado.

Palavras-chave:Investimentos financeiros. Rentabilidade. Tributos. Liquidez.

\begin{abstract}
This research had as its main objective to analyze the impact of taxation on the result of the profitability of the major investments and financial investments offered in the domestic financial market. For this a descriptive, documental and quantitative research was elaborated. The population constituted the main types of Investment and its Features demostrados in Folha de São Paulo. The study 's sample consisted of random way. The period to be analyzed, was the year 2010.In the study we used the investments available in the financial market and able to be profitable and callable in the short term, considering the initial value of $R \$ 100,000.00$. To analyze the data, we applied the technique of descriptive statistics. The results showed that the most significant profit was the dollar, gold and the NTN-B. But the high, medium and low-risk, respectively, need to be assessed in addition to the profits. The income tax and the administrative fees reduced the recommended investments from 12 to 6. Stressing that for its high risk the dollar ceases to be a viable option for the value and period considered. Despite the high value of the tax and medium risk, gold reached the highest profitability and liquidity and remained the most appropriate investment.
\end{abstract}

Keywords:Financial investments. Profitability. Taxes; Liquidity.

R. Eletr. do Alto Vale do Itajaí - REAVI, v. 5, n. 8, p. 01-13, dez., 2016

ISSN: 2316-4190, DOI: 10.5965/2316419005082016042 


\section{Introdução}

O Sistema Financeiro Nacional, regulamentado pelo Banco Central do Brasil, envolve bancos comerciais, de desenvolvimento, de investimentos e financeiros, que de maneira geral captam poupanças e disponibilizam empréstimos. Silveira (1995) apresenta que são os bancos, que interferem no dia-a-dia da economia por lançar créditos, captar depósitos, poupança e oferecer diferentes serviços à população, de forma a controlar, fiscalizar e determinar as medidas referentes à circulação da moeda e de crédito no país.

Historicamente os bancos impulsionam o desenvolvimento econômico. No Brasil, isso não tem ocorrido, devido a necessidade de financiamento do setor público e a compra de títulos da dívida interna do qual propicia às instituições bancárias a uma rentabilidade elevada e expressiva: nos últimos anos a taxa de juro realtem sido a mais elevada do mundo fazendo com que os bancos comprem os títulos públicos, ao invés de emprestar os recursos no mercado financeiro (CARNEIRO, 2002).

A taxa de juros tem três funções no mercado brasileiro: controlar a inflação, equilibrar a balança de pagamentos e a dívida pública. A taxa SELIC é que controla todas as demais taxas de juros no país e sua base de projeção é o valor da inflação (ASSAF NETO, 2014). A taxa dos bancos ainda sofre pressão dos spreads, que, segundo o CNI PEC (2003) corresponde à remuneração bruta do agente financeiro pelo desempenho de suas funções e constitui-se na diferença entre as taxas ativas do sistema bancário, isto é, a taxa de empréstimo cobrado do tomador de crédito, e a taxa de captação, que é a taxa à qual o poupador é remunerado.

Considerando a afirmação de Assaf Neto (2014) de que um investimento tem três aspectos principais: o risco, a rentabilidade e a liquidez; toma-se como proposição do estudo que, a rentabilidade maior, possivelmente está atrelada também a maiores riscos e prazos no investimento, considerando também outras características, como composição da carteira, tributação e outros possíveis custos. No entanto, pressupõe-se que o investimento identificado com menor rentabilidade no mercado financeiro tenha mais facilidade na liquidez, ou seja, permita velocidade para que o investidor se desfaça de seu investimento.

Alguns dos investimentos do mercado brasileiro, segundo a Folha de São Paulo (2010) são: $\mathrm{CDB} / \mathrm{RDB}$, debêntures, derivativos, dólar, fundos de ações, fundos de private equity, fundos de renda fixa, fundos multimercado, imóveis, obras de arte e antiguidades, ouro, poupança, previdência privada, títulos públicos. Além de se conhecer o tipo de investimento, todas as suas características, como composição da carteira e riscos, devem-se verificar a interferência da tributação na rentabilidade do investimento, e outros possíveis custos, para a partir disto tomar a decisão referente aos investimentos desejados.

No mercado financeiro há várias alternativas de investimento e aplicações, com remuneração, cobranças de impostos e taxas distintos que podem interferir no resultado final. Neste contexto, a questão que norteia a presente pesquisa é saber: qual o impacto da tributação no resultado dos investimentos e das aplicações financeiras? Para tanto, tem-se como objetivo analisar o impacto da tributação no resultado da rentabilidade dos principais investimentos e aplicações financeiras oferecidos no mercado financeiro nacional. Bem como, demonstrar a variação de rentabilidade obtida nos diferentes tipos de investimento do mercado financeiro nacional; simular a variação de rentabilidade, no período de 12 meses, deduzindo a tributação aplicada aos diferentes tipos de investimentos e considerar sua influência no patrimônio total. Ao fim comparar os melhores resultados de rentabilidade dos investimentos aos riscos e à liquidez.

Diante do exposto, justifica-se assim esta pesquisa, por ampliar as formas de identificar qual é o melhor investimento ou aplicação no mercado financeiro, tanto para pessoa física quanto jurídica, apontando a interferência da tributação nos resultados. Salienta-se que nem sempre isso é apontado ao investidor; e, considerando o elevado número de possibilidades de aplicação, 
muitas pessoas não incluem o aspecto tributário no resultado final, o que pode demandar perdas financeiras consideráveis.

\section{REFERENCIAL TEÓRICO}

Este capítulo tem como finalidade, fornecer embasamento teórico sobre o sistema financeiro, assim como as principais instituições que o compõem, iniciando com aspectos do mercado financeiro nacional e os principais tipos de investimentos e aplicações financeirasdisponíveis no mercado financeiro nacional, seus rendimentos e impostos devidos, para posteriormente aplicá-las na parte prática do estudo.

\subsection{Sistema e mercado financeiro nacional}

O Sistema Financeiro Nacional é formado por um conjunto de instituições, órgãos e afins que tem como finalidade controlar, fiscalizar e fazer medidas relacionadas à circulação da moeda e de crédito dentro do país. A Constituição Federal Brasileira (BRASIL, 1988, Art. 192) define o Sistema Financeiro Nacional como um órgão estruturado de forma promover o desenvolvimento equilibrado do país e a servir aos interesses da coletividade, em todas as partes que o compõem, e será regulado por leis complementares na participação do capital estrangeiro nas instituições que o integram.

Os conceitos e funções do SFN são atrelados entre si, sendo composto por instituições financeiras públicas e privadas que exercem funções no mercado financeiro, como resgatar recursos, distribuir e transferir os valores entre os agentes econômicos. Sendo assim, seu principal objetivo é viabilizar a relação entre os agentes deficitários de recursos e os agentes superavitários, capazes de gerar poupança. Nesse sentido o SFN faz essa conexão entre um e outro, oportunizando segurança e crescimento para o país (ASSAF NETO E LIMA, 2014).

O SFN é subdividido em órgãos normativos e órgão de intermediação. Na subdivisão do Sistema Financeiro, Assaf Neto (2014) diz que o subsistema normativo é constituído por instituições que estabelecem diretrizes de atuação das instituições financeiras operativas e controle do mercado. Alguns autores, como Assaf Neto e Lima (2014) detalham o tema e, conforme o BACEN (BRASIL, 2015) acrescenta ao sistema normativo, algumas instituições especiais, como o Banco do Brasil (BB), Banco Nacional de Desenvolvimento Econômico e Social (BNDES) e Caixa Econômica Federal (CEF).

Conforme Assaf Neto e Lima (2014), os órgãos de intermediação são compostos por instituições financeiras que efetuam a relação entre os agentes econômicos de forma operativa, tanto pessoas físicas ou jurídicas, governo e entidades diversas, que possuem disponibilidade de recursos para investimentos e os que necessitam de crédito. Os autores destacam ainda, que a forma de intermediação no mercado financeiro constitui-se em harmonizar os interesses em favor dos agentes econômicos superavitários em aplicar suas poupanças, e dos deficitários, em tomar recursos emprestados.

As instituições financeiras podem atuar de forma direta, ou seja, por conta própria, geralmente por bancos comerciais, ou de forma auxiliar, agindo em nome de terceiros. A instituição capta recursos no mercado pagando juros aos investidores. Com os recursos captados, efetua operações de empréstimos, cobrando uma taxa de juros. A diferença entre a taxa de juros cobradas dos tomadores de crédito e a paga aos aplicadores é chamada de spread. O spread precisa cobrir todas as despesas e riscos dos negócios realizados e remunerar a atividade de intermediação financeira (ASSAF NETO;LIMA, 2014).

As intermediações indiretas também são descritas pelos autores, como forma de auxiliar os deficitários e superavitários na realização de negócios. A instituição financeira não efetua 
diretamente a operação, não capta e nem aplica de modo direto os recursos. A instituição envolve-se na forma de auxiliar a aproximação entre as partes, atuando por conta dos agentes. Para a realização dessas tarefas é cobrada uma comissão pelos serviços prestados (ASSAF NETO; LIMA, 2014).

Para Mellagi Filho e Ishikawa (2014), as intermediações realizadas em bolsas de valores envolvem operações de longo prazo, como emissão e negociação de títulos de dívida, debêntures e de prazo indeterminado, como ações. Esse subsistema é dividido em cinco grandes grupos de instituições: Bancárias; Não bancárias; Sistema de Popança e Empréstimo-SBPE; Auxiliares e Instituições não bancárias.

O mercado financeiro promove a intermediação de recursos entre os agentes superavitários que gastam menos do que ganham, poupadores e os deficitários que gastam mais do que ganham, portanto, emprestam complementos para suas receitas. Segundo Megliorini e Vallim (2009), as empresas costumam alternar os dois papéis, e, por isso, é importante conhecer as aplicações e a forma de obtenção de recursos para cada caso.

Para Assaf Neto e Lima (2014) o mercado financeiro desenvolve-se de forma segmentada com base em quatro subdivisões estabelecidas para o mercado financeiro: Mercado Monetário, Mercado de Crédito, Mercado de Capitais, Mercado Cambial. Os autores ainda salientam que a subdivisão assume papel relevante na composição do mercado financeiro. No mercado monetário, são realizadas as operações de curto e curtíssimo prazo, e são negociados nesse mercado, principalmente, os papeis emitidos pelo tesouro nacional e com o intuito de financiar as necessidades orçamentárias da união, Estados e Municípios(ASSAF NETO E LIMA, 2014). Megliorini e Vallim (2009) mostram que esses papéis compõem e servem de parâmetro para a formação da taxa de juros básica da economia.

O mercado de crédito para Assaf Neto e Lima (2014) é constituído em sua essência pelos bancos comerciais/múltiplos. Ainda para os autores, seu objetivo básico é o de suprir as necessidades de recursos de curto e médio prazo dos diversos agentes econômicos, o que pode ser pela concessão de crédito às pessoas físicas, ou por modalidades de empréstimos e financiamento às pessoas jurídicas.

O mercado de capitais gera recursos de longo prazo e são investimentos com papel relevante no processo de desenvolvimento econômico. (ASSAF NETO e LIMA, 2014). Megliorini e Vallim (2009) ressaltam a ligação entre os agentes superavitários, que a atuação do mercado de capitais se processa ainda por operações de prazo indeterminado, como aquelas que envolvem emissão e subscrição de ações e debêntures.

No mercado cambial, Assaf Neto e Lima (2014) afirmam que ocorrem diversas operações de compra e venda de moedas estrangeiras conversíveis, englobando todos os agentes econômicos com motivos para realizar operações com o exterior, por exemplo, importadores e exportadores, investidores e instituições financeiras. Megliorini e Vallim (2009) complementam que a atuação do mercado cambial pode ocorrer em instituições financeiras autorizadas bancárias e não bancárias.

\subsection{Tipos de investimentos e rentabilidade}

Os tipos de investimentos como alternativas econômicas que prometem pagamentos de juros futuros, geralmente de longo prazo(Assaf Neto e Lima, 2014). A remuneração exigida por um investidor ao aplicar seus recursos denominados preço do dinheiro. Essa taxa depende basicamente do risco envolvido e do tempo da aplicação dos recursos, como curto, médio ou longo prazo. Megliorini e Vallim (2009) postulam que a taxa básica de juros que no Brasil é a definida pela Taxa SELIC é remunerada pelo governo no momento da venda de seus títulos no mercado. Essa taxa serve de referência para a formação das outras taxas de juros na economia, dispostas pelo Comitê de Política Monetária (COPOM) do Banco Central. Ainda, a rentabilidade 
pode ser entendida como o retorno esperado, sendo o ganho ou prejuízo de um investimento feito em determinado período.

$\mathrm{Na}$ visão de Assaf Neto (2014), a postura de um investidor perante o risco é de caráter pessoal, que depende do perfil do investidor, o qual pode realizar uma comparação racional de cada investimento antes de se arriscar e utilizar alternativas financeiras disponíveis para se construir uma escala de preferência de investimentos. Esta escala é composta por comparações e percepções de diferentes indivíduos, referente a seus traços psicológicos, características individuais, conhecimento e maneira de enfrentar o risco.

Segundo Cavalcante, Misumi e Rudge (2009) as instituições financeiras oferecem ao mercado uma gama diferenciada de alternativas, para atender a seus clientes de acordo com sua aceitação ou aversão ao risco. Essas oferecem ao investidor a administração profissional de seus investimentos e condições para que esse, detendo informações seguras, possa decidir melhor quanto às opções de investimento.

As opções mais comuns no mercado estão mostradas pelo Quadro 1, que descreve o tipo de investimento, rentabilidade, risco e liquidez alcançada em cada opção.

Quadro 1: Principais tipos de investimentos e suas características

\begin{tabular}{|l|l|l|l|}
\hline \multicolumn{4}{|c|}{ Principais tipos de investimento e suas características } \\
\hline \multicolumn{1}{|c|}{ Tipo de investimento } & \multicolumn{2}{c|}{ Rentabilidade } & \multicolumn{1}{c|}{ Liquidez } \\
\hline Ações de grandes empresas & Média & Médio & Alta \\
\hline Ações smallcaps & Alta & Alto & Média \\
\hline CDB/RDB & Baixa & Muito baixo & Média \\
\hline Debêntures & Média & Baixo & Média \\
\hline Derivativos & Muito alta & Muito alto & Alta \\
\hline Dólar ou outras moedas & Média & Alto & Muito alta \\
\hline Fundos de ações & Alta & Médio & Alta \\
\hline Fundos de private equity & Alta & Alto & Baixa \\
\hline Fundos de renda fixa & Baixa & Baixo & Média \\
\hline Fundos multimercado & Média & Médio & Média \\
\hline Imóveis & Média & Baixo & Muito baixa \\
\hline Obras de arte e antiguidades & Baixa & Médio & Muito baixa \\
\hline Ouro & Média & Médio & Alta \\
\hline Poupança & Muito baixa & Muito baixo & Muito alta \\
\hline Previdência privada & Média & Baixo & Média \\
\hline Títulos públicos & Baixa & Baixo & Alta \\
\hline
\end{tabular}

Fonte: Folha de São Paulo (2010, p. 1).

No entender de Assaf Neto (2006) o certificado de depósito bancário (CDB) é uma obrigação de pagamento futuro de um capital aplicado em depósito a prazo fixo em instituições financeiras. Destinados ao financiamento de capital de giro das empresas têm os títulos emitidos em função do volume de crédito demandado pelas empresas. O CDB pode ser emitido com remuneração pré-fixada ou pós-fixada permitindo que se saiba quanto será pago no vencimento, no CDB pré-fixado. Um CDB pós-fixado contém seus rendimentos formados por um índice de preços de mercado mais uma taxa real de juro pactuada no momento da aplicação. Sobre os rendimentos produzidos pelo $\mathrm{CDB}$ incide imposto de renda na fonte (MELLAGI FILHO; ISHIKAWA, 2014).

Os certificados de depósitos interfinanceiros (CDI) são títulos emitidos pelas instituições financeiras entre si, elas compõem um mercado interfinanceiro como compradoras e vendedoras de dinheiro. Normalmente as taxas negociadas não sofrem intervenções oficiais diretas, são definidas diariamente, amplamente divulgadas pela imprensa e são formadas com base nas taxas de juros reais do mercado de títulos públicos e nas taxas de inflação da economia (ASSAF NETO, 2006). 
Na prática, Megliorini e Vallim (2009) apontam que o CDI mede o custo do dinheiro para empréstimos entre os bancos. Por isso, assim como a Taxa Selic, serve de referencial na formação de juros no mercado. Para Cavalcante e Misumi (2009), os fundos de investimentos cobram de seus cotistas diversos encargos, como a taxa de administração da instituição financeira, taxa de performance e taxa referente ao ingresso e saída (MEGLIORINI; VALLIM, 2009). A remuneração desses fundos varia diariamente e o valor de cada cota é divulgado diariamente, sendo obtido pela relação entre o valor do patrimônio líquido do fundo e seu número de cotas.

Conforme Assaf Neto e Lima (2014) o investimento mais popular do Brasil é a caderneta de poupança, sua remuneração é fixada em média $0,5 \%$ ao mês de juros mais a variação da Taxa Referencial (TR). Para pessoas físicas os juros são creditados mensalmente, e às pessoas jurídicas, trimestralmente. Têm liquidez imediata, conta com a isenção de imposto de renda sobre os ganhos e a ausência de taxas de administração. Os juros pagos e os valores da taxa referencial e da taxa básica financeira são correspondentes ao primeiro dia útil de cada mês.

A previdência privada de acordo com Megliorini e Vallim (2009) tem como característica a adesão opcional, ao contrário da previdência social, que é de caráter público e obrigatório. Classificada como um seguro de renda e oferecem planos e benefícios de aposentadoria, morte e invalidez. O objetivo básico da aquisição de um plano de previdência privada é a manutenção do padrão de vida, mas as limitações a levam a ser usada para garantir a subsistência das pessoas. Dentro do sistema de previdência privada destacam-se dois planos: o Plano gerador de benefícios livres (PGBL); e o Plano de vida gerador de benefícios livres (VGBL). O VGBL e o PGBL possuem diferenças, conforme resume o Quadro 2.

Quadro 2: Diferença entre PGBL e VGBL

\section{PGBL}

VGBL

Aceita contribuições mensais e/ou esporádicas, de $\quad$ Aceita contribuições mensais e/ou esporádicas, de acordo acordo com a disponibilidade. com a disponibilidade.

Pode realizar contribuições adicionais a qualquer Pode realizar contribuições adicionais a qualquer momento. momento.

Em caso de morte do participante, o saldo Em caso de morte, o saldo acumulado será resgatado acumulado poderá ser resgatado pelo beneficiário.

As contribuições efetuadas são dedutíveis da declaração do imposto de renda, até o limite de

$12 \%$ de seu rendimento bruto anual. beneficiários.

Durante o período de acumulação, os recursos contribuídos estão isentos de tributação sobre os rendimentos. No recebimento de renda ou resgate, o imposto de renda incide somente sobre os rendimentos e não sobre todo o montante, o que pode gerar um ganho importante na performance ao final do período de acumulação. (Conforme legislação em vigor).

$100 \%$ da rentabilidade líquida obtida é repassada. $100 \%$ da rentabilidade líquida obtida é repassada.

Conta com alguns tipos de composição de fundos Conta com alguns tipos de composição de fundos de de investimento de acordo com seu perfil. investimento de acordo com seu perfil.

Fonte: Adaptado de Assaf Neto (2006).

Segundo a Receita Federal do Brasil (2015) existem dois tipos de tributação para o VGBL e o PGBL: a tributação do IR ou tabela regressiva, baseado em tempo de acumulação de recursos; e a tabela progressiva anual, baseada em limite de valores.

A Letra de Crédito Imobiliário (LCI) e a Letra de Crédito do Agronegócio (LCA) são dois tipos de investimentos em renda fixa isentos de imposto de renda para pessoas físicas que costumam garantir retornos superiores ao da caderneta de poupança. Em caso de quebra do banco, esses títulos são garantidos pelo Fundo Garantidor de Crédito até R\$ 250 mil, só podem ser resgatados no seu vencimento (INFOMONEY, 2015).

Quanto à rentabilidade das LCI pós-fixados, o investidor receberá um percentual do CDI, que oscila de acordo com a taxa SELIC, no entanto se a opção for por LCI prefixadas, saberá o 
valor do rendimento no ato da aplicação, independente da oscilação do CDI. Já a LCA, define como títulos emitidos por bancos garantidos por empréstimos concedidos ao agronegócio. Esses títulos foram criados pelo governo com o objetivo de ampliar os recursos disponíveis ao financiamento agropecuário. Quanto à rentabilidade a LCA pode ser definida por taxa de juro pré ou pós-fixada da mesma maneira que a LCI e possuem isenção do IR e IOF (ASSAF NETO, 2014).

As ações são definidas como frações de capital de uma empresa, que pode ser de capital aberto ou fechado. Empresas com esse perfil são chamadas de sociedades anônimas. Mellagi Filho e Ishikawa (2014) explicam que essas empresas "são regulamentadas pela Lei $\mathrm{n}^{0}$ 6.404, de 15 de dezembro de 1976. A empresa de capital aberto e tem a obrigação de prestar informações periódicas ao mercado sobre seu comportamento social, econômico e financeiro". E ainda classificadas como ordinárias e preferenciais. Quanto aos ganhos obtidos nas ações vem da valorização das mesmas e dos recebimentos dos dividendos distribuídos, Megliorini e Vallim (2009) destacam a cobrança de taxas e emolumentos, além do IR de 15\%.

O Tesouro Direto é um programa que efetua vendas de títulos públicos pela internet, a pessoas físicas, desenvolvido pelo Tesouro Nacional, em conjunto com a Companhia Brasileira de Liquidação e Custódia (CBLC). Os títulos públicos são ativos de renda fixa, que são opções de investimento seguro para a sociedade. Entre as vantagens estão: alta rentabilidade; baixas taxas de administração; investimentos diversificados, obtendo rentabilidades variadas, como pósfixadas (pela taxa básica da economia), pré-fixadas e indexadas à índices de preços; a escolha do melhor prazo para a aplicação que deseja; a garantia da liquidez; maior controle do patrimônio; e o baixo risco que os títulos públicos oferecem.

No Tesouro Direto, pode-se optar por adquirir títulos públicos pré-fixados e pós-fixados. Os títulos pré-fixados possuem rentabilidade definida no momento da compra e os títulos pósfixados possuem valor corrigido por um indexador, a rentabilidade da aplicação depende do desempenho desse indexador e da taxa contratada no momento da compra. A taxa de custódia é de $0,30 \%$ a.a. (valor baixo, se comparado aos valores aplicados pelas instituições bancárias) sobre o valor dos títulos, que referem-se aos serviços de guarda dos títulos e às informações e movimentações dos saldos. A partir da compra, os títulos públicos ficam guardados em uma conta de custódia na BMF\&BOVESPA em nome do titular, aberta pelo agente de custódia (instituição financeira), podendo o titular trocar de instituição em qualquer momento sem prejudicar sua aplicação (BRASIL, 2015).

$\mathrm{Na}$ compra do ouro o investidor deve escolher uma corretora de sua preferência que o encaminha para um fundidor autorizado e credenciado pela BM\&FBovespa para transformar seu ouro em barras. Os custos envolvem taxas de corretagem; taxa de custódia; seguro para o transporte de barras e incidência de Imposto de Renda em aplicações superiores a R \$ 20 mil por mês. Por ser uma mercadoria que obedece às leis da oferta e procura, e por isso variável, é vinculada às cotações da Bolsa de Valores de Londres e a Bolsa de Valores de Nova York, e sofre influência direta do dólar, sobretudo, o flutuante, chegando a variar $2 \%$ para mais ou para menos (BM\&FBOVESPA, 2015).

A cotação do dólar é apresentada diariamente pelos meios de comunicação e orienta as transações do mercado nacional e internacional (BACEN, 2015). De acordo com a Receita Federal do Brasil (2015) o imposto de renda sobre os ganhos em reais obtidos na alienação da moeda estrangeira é de $15 \%$ a $22,5 \%$ sob a forma de ganho de capital a depender do prazo de aplicação; de IOF a alíquota é de 6,38\% sobre aplicações inferiores a 30 dias, assim como taxas de administração que variam de acordo com instituição.

Segundo dados do BACEN (2015), os imóveis são formas seguras e de baixo risco para preservar um patrimônio. Um imóvel pode valorizar mais o investimento em relação à rentabilidade de investimentos mais conservadores, como a caderneta de poupança ou um fundo 
de investimento DI. No Brasil, a partir de 2005 pelo potencial crescimento, o mercado mostrouse um cenário favorecido para opção de investimento rentável em imóveis.

Os rendimentos oriundos do aluguel de imóveis são tributados com alíquotas de imposto de renda aplicadas progressivamente e variam de zero a 27,5\%. Segundo Assaf Neto (2004), despesas relacionadas ao imóvel podem ser deduzidas, tais como taxa de administração, taxa condominial e IPTU. Nas vendas de imóveis efetuadas por pessoa física o tributo a ser pago é o imposto de renda sobre o ganho de capital. Esse tributo só é devido quando o valor de venda do imóvel é superior ao seu valor histórico. Para imposto de renda aplica-se a alíquota de $15 \%$ sobre o lucro da operação (ganho de capital) (BACEN, 2015).

Além de conhecer a tipologia do investimento, faz-se necessário conhecer os impostos que incidem sobre eles, que são: o Imposto Sobre Operações Financeiras (IOF) e o Imposto de Renda (IR).O imposto sobre operações financeiras (IOF) incide sobre o valor do rendimento auferido. Este imposto, no entanto, somente é devido quando ocorrerem resgates antes que a aplicação complete 30 dias. (ASSAF NETO; LIMA, 2014). O imposto de renda (IR) é um tributo cobrado pela Receita Federal utilizando-se como base de cálculo os rendimentos na maioria dos casos. Dessa forma o investidor consegue analisar a rentabilidade líquida de um investimento e tomar a decisão correta sobre o investimento a ser feito.

\section{METODOLOGIA}

A partir do objetivo do estudo em analisar o impacto da tributação no resultado da rentabilidade dos principais investimentos e aplicações financeiras oferecidos no mercado financeiro nacionalelaborou-se uma pesquisa descritiva, documental e quantitativa. A pesquisa de recolhimento dos dados aconteceu durante a primeira quinzena de novembro de 2015, sendo por meio de consultas a diferentes relatórios oficiais, em diferentes instituições bancárias, não bancárias e órgãos governamentais, sobretudo em sites dessas instituições. Dos quais foram selecionadas as principais aplicações disponíveis no mercado financeiro brasileiro e sendo composta pelas que se encaixavam como investimento capaz de ser rentável e resgatável em curto prazo (12 meses), considerando o valor de $\mathrm{R} \$ 100.000,00$. Os relatórios compreendiam o período de novembro de 2014 a outubro de 2015. Com base nos dados coletados, foram identificadas doze variáveis de rentabilidade dispostas no Quadro 3, as quais serviram de base para os cálculos posteriores relevantes à pesquisa.

Quadro 3 - Variáveis da pesquisa

\begin{tabular}{|c|c|}
\hline \multicolumn{1}{|c|}{ INVESTIMENTOS } \\
\hline Ações da Ibovespa & LCA - 90\% do CDI \\
\hline Poupança & Fundo de Investimento DI \\
\hline Imóveis- CUB & LTN Pré \\
\hline Previdência Privada VGBL Renda Fixa & NTN-B IPCA \\
\hline CDB - 90\% CDI & OZ1D - Ouro BM\&F \\
\hline LCI - 90\% do CDI & DOLZ15 - Dólar BM\&F \\
\hline
\end{tabular}

Fonte: Dados da pesquisa

Aplicou-se a técnica da estatística descritiva para a análise, cujo objetivo básico é o de sintetizar uma série de valores de mesma natureza, permitindo desta forma que se tenha uma visão global da variação desses valores, organizando e descrevendo os dados de três maneiras: por meio de tabelas, quadros e medidas descritivas. As tabelas e quadros resumem um conjunto de observações, de forma a produzir uma impressão rápida e viva do fenômeno em estudo (HAIR JR. et al., 2005).

Nesse contexto, para um observador leigo, ou pouco informado, a melhor opção para investimento financeiro é o dólar e o ouro. Segundo a BM\&F (2015), o ouro sofre interferência 
do dólar nas cotações da Bolsa de Valores de Londres e Nova York, sobretudo do dólar flutuante, chegando a variar $2 \%$ para mais ou para menos. No entanto, para considerar a melhor aplicação é preciso observar também o risco do investimento. Ele pode ser uma forma de analisar como o investidor pretende correr riscos em relação ao seu patrimônio. Na visão de Assaf Neto (2014), a postura de um investidor perante o risco é de caráter pessoal, ele pode realizar uma comparação racional de cada investimento antes de se arriscare utilizar alternativas financeiras disponíveis para construir uma escala de preferênciade investimentos. Os riscos decorrentes da rentabilidade dos investimentos financeiros são mostrados pela Tabela 6, que acrescenta a informação a cada tipo de aplicação.

Tabela 1: Rentabilidade e risco dos investimentos financeiros

\begin{tabular}{l|c|l}
\hline \multicolumn{1}{c|}{ Investimento } & Rentabilidade & \multicolumn{1}{c}{ Risco } \\
\hline Ações da Ibovespa & $-13,71 \%$ & Médio \\
\hline Imóveis - CUB & $7,73 \%$ & Baixo \\
\hline Poupança & $7,66 \%$ & Muito Baixo \\
\hline Previdência Privada VGBL Renda Fixa & $9,45 \%$ & Baixo \\
\hline CDB - 90\% CDI & $11,47 \%$ & Muito Baixo \\
\hline LCI - 90\% do CDI & $11,47 \%$ & Baixo \\
\hline LCA - 90\% do CDI & $11,47 \%$ & Baixo \\
\hline Fundo de Investimento DI & $12,01 \%$ & Baixo \\
\hline LTN Pré & $14,97 \%$ & Baixo \\
\hline NTN-B IPCA & $17,58 \%$ & Baixo \\
\hline OZ1D - Ouro BM\&F & $44,02 \%$ & Médio \\
\hline DOLZ15 - Dólar BM\&F & $46,87 \%$ & Alto \\
\hline Fon
\end{tabular}

Fonte: Adaptado pelas autoras dos dados da pesquisa.

Avaliando os dados de rentabilidade e risco, o ouro passa a ser um investimento de risco médio e o dólar de alto risco, o que pode comprometer o resgate e a rentabilidade dos investimentos. As ações da Ibovespa possuem risco médio. As demais opções de investimento possuem risco baixo ou muito baixo, e, por isso, tornam-se também investimentos atraentes, sobretudo se o tempo de resgate do valor investido for considerado baixo (de 6 meses a 2 anos).

Para a tomada de decisão correta é preciso considerar ainda os tributos cobrados sobre o valor das aplicações e verificar sua influência e impacto no valor da rentabilidade final. Para melhor esclarecer esse aspecto, observa-se o item a seguir, que detalha o assunto atendendo ao segundo objetivo específico desse estudo.

Para atender ao segundo objetivo específico desse estudo foi simulada a variação de rentabilidade, no período de 12 meses, deduzindo a tributação aplicada aos diferentes tipos de investimentos e considerada sua influência no patrimônio total. Os investimentos foram simulados com um valor de aplicação inicial de $\mathrm{R} \$ 100.000,00$ (cem mil reais) e um prazo de 12 meses (considerando dados de novembro de 2014 a outubro de 2015). Os resultados dos percentuais de Impostos de Renda (IR) e taxas cobrados em cada opção de investimento são mostrados pela Tabela 7 .

Tabela 2: Imposto de Renda e taxas cobradas para investimento de R\$100.000 em 12 meses

\begin{tabular}{l|c|c|c}
\multicolumn{1}{c|}{ Produto } & \% de IR & Taxa Administrativa & Valor do IR Retido \\
\hline CDB & $20 \%$ & Não possui & $2.294,77$ \\
\hline Fundo de Investimento DI & $20 \%$ & $1 \%$ (já deduzida) & $2.402,00$ \\
\hline Poupança & Isento & Não possui & - \\
\hline Previdência Privada VGBL & $15 \%$ & $2,8 \%$ & $1.417,50$ \\
\hline LCI - 90\% do CDI & Isento & Não possui & - \\
\hline LCA - 90\% do CDI & Isento & Não possui & - \\
\hline Ações da Ibovespa & $15 \%$ & $\begin{array}{c}14,90(\text { corretagem) }+0,0050 \%+ \\
0,0275 \% \text { taxa custodia }=43,63\end{array}$ \\
\hline
\end{tabular}




\begin{tabular}{l|c|c|c}
\hline LTN Pré & $20 \%$ & $0,5 \%(-574,85)$ & 2994,00 \\
\hline NTN-B IPCA & $20 \%$ & $0,5 \%(-587,90)$ & $3.516,00$ \\
\hline OZ1D - Ouro BM\&F & $15 \%$ & $0,6 \%(-264,12)$ & $6.603,00$ \\
\hline DOLZ15 - Dólar BM\&F & $15 \%$ & 2,00 por contrato(-16,26) & $7.030,50$ \\
\hline Imóveis & $15 \%$ & $2 \%$ (ITBI) $(-2.154,60)$ & $1.159,50$
\end{tabular}

Fonte: Cálculo efetuado pela autora sobre os valores pesquisados. Obs.: O VGBL: como o simulado foi de um ano o resgate é antecipado. Nesse caso, o IR é alíquota única de $15 \%$.

A Tabela 7 aponta que o dólar possui o maior índice de cobrança de imposto de renda de todos os investimentos avaliados, onde as taxas cobradas são referentes a $\mathrm{R} \$ 2,00$ por contrato, nesse caso são 8 contratos no momento da compra em novembro/2014, quando o valor do dólar era cotado em $\mathrm{R} \$ 2,46$. O valor do ouro também se apresenta com margem alta de imposto, seguido pela NTN-B e pela LTN Pré. O CDB, poupança e as letras de câmbio LCI e LCA não possuem taxas administrativas. No entanto, a LCI e a LCA possuem títulos que só podem ser resgatados no dia do vencimento e o dinheiro não poderá ser movimentado até lá, ou seja, é preciso ater-se às datas para efetuar o resgate.

Para melhor compreender como os valores cobrados pelo IR e pelas taxas de administração interferem no ganho real ao investidor, observa-se a Tabela 8 , que apresenta os dados comparativos.

Tabela 3: Rentabilidade líquida e efetiva após a dedução das taxas e imposto de renda

\begin{tabular}{l|l|c|c|c}
\hline Produto & $\begin{array}{l}\text { Rentabilidade } \\
\text { Bruta }\end{array}$ & $\begin{array}{c}\text { Valor Líquido } \\
\text { Sem IR e Taxas }\end{array}$ & $\begin{array}{c}\text { Rentabilidade } \\
\text { Bruta do Período }\end{array}$ & $\begin{array}{c}\text { Rentabilidade } \\
\text { Efetiva após os } \\
\text { impostos }\end{array}$ \\
\hline CDB & $111.473,83$ & $109.179,06$ & $11,47 \%$ & $9,18 \%$ \\
\hline Fundo de Investimento DI & $112.010,00$ & $109.608,00$ & $12,01 \%$ & $9,61 \%$ \\
\hline Poupança & $110.766,00$ & $110.766,00$ & $6 \%+7 R(1,66 \%)$ & $7,66 \%$ \\
\hline Previdência Privada VGBL & $109.450,00$ & $107.767,90$ & $9,45 \%$ & $7,77 \%$ \\
\hline LCI - 90\% do CDI & $111.473,83$ & $111.473,83$ & $11,47 \%$ & $11,47 \%$ \\
\hline LCA - 90\% do CDI & $111.473,83$ & $111.473,83$ & $11,47 \%$ & $11,47 \%$ \\
\hline Ações da Ibovespa & $86.290,00$ & $86.246,37$ & $-13,71 \%$ & $0,00 \%$ \\
\hline LTN Pré & $114.970,00$ & $111.401,15$ & $14,97 \%$ & $11,40 \%$ \\
\hline NTN-B IPCA & $117.580,00$ & $113.476,10$ & $17,58 \%$ & $13,48 \%$ \\
\hline OZ1D - Ouro BM\&F & $144.020,00$ & $137.152,88$ & $44,02 \%$ & $37,15 \%$ \\
\hline DOLZ15 - Dólar BM\&F & $146.870,00$ & $139.823,24$ & $46,87 \%$ & $39,82 \%$ \\
\hline Imóveis & $107.730,00$ & $104.415,90$ & $7,73 \%$ & $4,42 \%$
\end{tabular}

Fonte: Dados da pesquisa.

Ao considerar a rentabilidade efetiva do período, os investimentos em imóveis alcançam valores inferiores à poupança, que é avaliada como um investimento de baixa rentabilidade. As ações da Ibovespa não apresentam ganhos, ao contrário, subtraem valores expressivos do investimento inicial. O VGBL embora seja apresentado como um investimento com um rendimento de 9,45\%, após a dedução dos impostos e taxas não apresenta um rendimento considerável, a saber, seu rendimento real é de $7,77 \%$, o que o torna um pouco mais atraente do que os resultados da poupança (que é de 7,66\%). Considerando-se os valores reais apresentados pela Tabela 8 observa-se que o imposto tem um impacto capaz de interferir negativamente no ganho real de muitos tipos de investimento.

Assim, tornam-se opções atraentes ao investidor, segundo o valor calculado por esse projeto e o tempo de 12 meses, as opções demonstradas pela Tabela 9.

Tabela 4: As melhores opções de investimento para o valor de R $\$ 100.000$ em 12 meses

\begin{tabular}{c|c|c|c|c}
\hline Produto & $\begin{array}{c}\text { Rentabilidade } \\
\text { Bruta }\end{array}$ & $\begin{array}{c}\text { Valor Líquido } \\
\text { Sem IR e Taxas }\end{array}$ & $\begin{array}{c}\text { Rentabilidade do } \\
\text { Período }\end{array}$ & $\begin{array}{c}\text { Rentabilidade } \\
\text { Efetiva após os }\end{array}$ \\
\hline
\end{tabular}




\begin{tabular}{l|l|l|l|c}
\hline & & & & impostos \\
\hline LTN Pré - 15.1\% a.a. & $114.970,00$ & $111.401,15$ & $14,97 \%$ & $11,40 \%$ \\
\hline LCA - 90\% do CDI & $111.473,83$ & $111.473,83$ & $11,47 \%$ & $11,47 \%$ \\
\hline LCI - 90\% do CDI & $111.473,83$ & $111.473,83$ & $11,47 \%$ & $11,47 \%$ \\
\hline NTN-B IPCA & $117.580,00$ & $113.476,10$ & $17,58 \%$ & $13,48 \%$ \\
\hline OZ1D - Ouro BM\&F & $144.020,00$ & $137.152,88$ & $44,02 \%$ & $37,15 \%$ \\
\hline DOLZ15 - Dólar BM\&F & $146.870,00$ & $139.839,50$ & $46,87 \%$ & $39,84 \%$ \\
\hline
\end{tabular}

Fonte: Dados da pesquisa.

Dentro do contexto apresentado pela Tabela 9, o LTN Pré possui o menor rendimento $(11,40 \%)$. A LCI e a LCA são as únicas opções que apresentam rentabilidade anunciada real, ou seja, não aplicam a cobrança de impostos e taxas e não terão os valores de ganhos alterados ao fim do período. O ouro e o dólar, embora apresentem perda de ganho real a partir do valor anunciado (cerca de 7 pontos percentuais), ainda se apresentam como as melhores opções de investimento, ultrapassando em mais de $25 \%$ o ganho real obtido nas aplicações das letras de câmbio (LCI e LCA).

No entanto, o patrimônio total ao fim de 12 meses deve levar em consideração não só a rentabilidade, mas, o tipo de risco que a aplicação oferece. A escolha do risco está contida no perfil do investidor, que Camilo (2012) explica que pode ser conservador, moderado e agressivo. Para resgatar um investimento ao fim de um curto período (6 meses a 2 anos) também é necessário analisar a liquidez do investimento, ou seja, a rapidez com que se pode reaver o valor investido acrescido dos devidos lucros. A rentabilidade do investimento, assim como os riscos e a liquidez estão detalhados pelo item a seguir que os compara para analisar o terceiro objetivo específico desse projeto.

O terceiro objetivo específico buscou comparar os melhores resultados de rentabilidade aos riscos de cada investimento e à liquidez que o investimento possibilita. Assaf Neto e Lima (2014) ressaltam que os riscos estão incluídos nos valores cobrados dos investidores. A diferença entre a taxa de juros cobrada dos tomadores de crédito e aquela paga aos aplicadores é que cobre todas as despesas e riscos dos negócios realizados.

Mas, para considerar os riscos, também se deve avaliar o prazo do investimento. Ele altera o tipo de aplicação a ser feita e pode interferir consideravelmente nos valores da rentabilidade efetiva (descontados os impostos devidos) e a facilidade ou não de reaver o valor investido (liquidez). Nesse contexto, três possibilidades se apresentam conforme Camilo (2012): o resgate em curto prazo (até 2 anos), o resgate em média prazo (de 2 a 5 anos), ou o investimento em longo prazo (de 5 anos em diante). Para avaliar a simulação proposta por esse estudo considera-se o resgate do valor após o período de 12 meses (curto prazo), embora possa ser avaliada a possibilidade de reaplicação do investimento.

Inicialmente ao organizar as informações das aplicações por risco de investimento obtémse a Tabela 10, que apresenta os dados a serem observados pelo investidor.

Tabela 5: Investimentos e seus níveis de risco

\begin{tabular}{l|l|l|l}
\hline \multicolumn{1}{c|}{ Risco Muito Baixo } & \multicolumn{1}{|c|}{ Risco Baixo } & \multicolumn{1}{c}{ Risco Médio } & \multicolumn{1}{c}{ Risco Alto } \\
\hline Poupança & Imóveis- CUB & OZ1D - Ouro BM\&F & DOLZ15 - Dólar BM\&F \\
\hline CDB & VGBL Renda Fixa & Ações da Ibovespa & \\
\hline & LCI & & \\
\hline & LCA & & \\
\hline & Fundo de Investimento & & \\
\hline & LTN Pré & & \\
\hline & NTN-B & & \\
\hline
\end{tabular}

Fonte: Elaborado pelas autoras. 
O BACEN (2015) e alguns autores como Assaf Neto (2014), e Mellagi Filho e Ishikawa (2014) recomendam que quando o investimento necessita de resgate em tempo determinado curto e o valor aplicado for médio ou alto, o risco deve ser muito baixo, baixo ou médio. Dessa forma, nessa análise e observando a Tabela 10, o dólar está descartado como investimento se considerada a possibilidade de resgate em 12 meses, pois apresenta alto risco. O resultado negativo das Ações Ibovespa também a coloca como um investimento de risco. Os imóveis, com ganho real menor do que a poupança quando abatido o imposto devido (apesar do baixo risco), também os tornam investimentos pouco significativo para o valor e o período em que se deve realizar o resgate (12 meses). Dessa forma, são opções viáveis de investimento em curto prazo a LCI, a LCA, o LTN Pré, o NTN-B (de risco baixo) e o ouro (de risco médio). No entanto, para melhor compreender qual o rendimento obtido entre essas opções, o risco e a liquidez desses tipos de investimento observa-se a Tabela 11.

Tabela 6: Avaliação do risco e liquidez das melhores opções de rendimento para resgate em curto prazo

\begin{tabular}{l|c|c|c|c}
\multicolumn{1}{c|}{ Produto } & $\begin{array}{c}\text { Valor Real com Imposto } \\
\text { Deduzido (R\$) }\end{array}$ & Rentabilidade & Risco & Liquidez \\
\hline $\begin{array}{l}\text { OZ1D - Ouro } \\
\text { BM\&F }\end{array}$ & $137.152,88$ & Média & Médio & Alta \\
\hline LCI - 90\% do CDI & $111.473,83$ & Baixa & Baixo & Baixa \\
\hline LCA - 90\% do CDI & $111.473,83$ & Baixa & Baixo & Baixa \\
\hline LTN Pré & $111.401,15$ & Baixa & Baixo & Alta \\
\hline NTN-B & $113.476,10$ & Baixa & Baixo & Alta \\
\hline
\end{tabular}

Fonte: Dados da pesquisa.

A baixa rentabilidade e liquidez dos investimentos da LCI e LCA se devem principalmente ao fato de que o título é pré-fixado e só pode ser resgatado no vencimento, segundo (RIFFEL, 2016). O dinheiro não poderá ser movimentado até o prazo, ou seja, não se pode perder o prazo do resgate e não há possibilidade de resgate fora da data pré-estabelecida. Considerando a baixa liquidez é um investimento perigoso para curto prazo, caso o investidor precise do dinheiro antes ou após a data limite, apesar do baixo risco. A alta liquidez e baixo risco são oferecidos pelos investimentos do Tesouro Direto (NTN/LTN), conforme os achados de (RIFFEL, 2016). Embora a rentabilidade seja pré-estabelecida e considerada baixa, para um retorno em curto prazo se torna uma opção recomendada. Em longo prazo pode se apresentar como um fundo de renda fixa de rentabilidade média.

O ouro, por conseguinte, apesar de oferecer médio risco, possui a mais alta rentabilidade e também apresenta alta liquidez. Dessa forma, cabe analisar a variação do preço do ouro nos últimos 12 meses para verificar a variação na cotação e a possibilidade de esse investimento se tornar um risco mesmo em curto período de tempo. A Tabela 12 mostra a cotação do ouro nos últimos 12 meses e a variação obtida.

Tabela 7: Variação do ouro nos últimos 12 meses

\begin{tabular}{l|r|r|r|r|r|r}
\hline Data & Último & Abertura & Máxima & Mínima & Vol. & Var\% \\
\hline $\mathbf{0 1 . 1 1 . 2 0 1 5}$ & 1077.00 & 1141.40 & 1142.60 & 1064.50 & - & $\mathbf{- 5 . 6 5 \%}$ \\
\hline $\mathbf{0 1 . 1 0 . 2 0 1 5}$ & 1141.50 & 1115.20 & 1189.00 & 1105.80 & $4,19 \mathrm{~K}$ & $\mathbf{2 . 3 3 \%}$ \\
\hline $\mathbf{0 1 . 0 9 . 2 0 1 5}$ & 1115.50 & 1133.50 & 1155.90 & 1098.20 & $4,78 \mathrm{~K}$ & $\mathbf{- 1 . 4 2 \%}$ \\
\hline $\mathbf{0 1 . 0 8 . 2 0 1 5}$ & 1131.60 & 1095.50 & 1169.00 & 1080.50 & $12,82 \mathrm{~K}$ & $\mathbf{3 . 3 5 \%}$ \\
\hline $\mathbf{0 1 . 0 7 . 2 0 1 5}$ & 1094.90 & 1173.10 & 1173.10 & 1078.60 & $57,76 \mathrm{~K}$ & $\mathbf{- 6 . 5 4 \%}$ \\
\hline $\mathbf{0 1 . 0 6 . 2 0 1 5}$ & 1171.50 & 1190.60 & 1204.00 & 1163.30 & $5,98 \mathrm{~K}$ & $\mathbf{- 1 . 5 0 \%}$ \\
\hline $\mathbf{0 1 . 0 5 . 2 0 1 5}$ & 1189.40 & 1178.10 & 1228.10 & 1170.00 & $57,93 \mathrm{~K}$ & $\mathbf{0 . 5 9 \%}$ \\
\hline $\mathbf{0 1 . 0 4 . 2 0 1 5}$ & 1182.40 & 1182.90 & 1224.20 & 1174.60 & $7,45 \mathrm{~K}$ & $\mathbf{- 0 . 0 6 \%}$ \\
\hline $\mathbf{0 1 . 0 3 . 2 0 1 5}$ & 1183.10 & 1214.30 & 1222.70 & 1144.30 & $42,95 \mathrm{~K}$ & $\mathbf{- 2 . 4 3 \%}$ \\
\hline $\mathbf{0 1 . 0 2 . 2 0 1 5}$ & 1212.60 & 1284.10 & 1284.70 & 1191.60 & $7,75 \mathrm{~K}$ & $\mathbf{- 5 . 1 5 \%}$ \\
\hline
\end{tabular}




\begin{tabular}{c|r|r|r|r|r|r}
\hline 01.01.2015 & 1278.50 & 1184.00 & 1303.50 & 1169.50 & $78,26 \mathrm{~K}$ & $\mathbf{7 . 9 9 \%}$ \\
\hline $\mathbf{0 1 . 1 2 . 2 0 1 4}$ & 1183.90 & 1160.00 & 1238.00 & 1141.70 & $11,02 \mathrm{~K}$ & $\mathbf{0 . 7 4 \%}$ \\
\hline $\mathbf{0 1 . 1 1 . 2 0 1 4}$ & 1175.20 & 1166.40 & 1202.40 & 1132.90 & $88,66 \mathrm{~K}$ & $\mathbf{0 . 3 5 \%}$ \\
\hline $\mathbf{0 1 . 1 0 . 2 0 1 4}$ & 1171.10 & 1207.70 & 1247.00 & 1161.40 & $3,88 \mathrm{~K}$ & $\mathbf{- 3 . 2 5 \%}$ \\
\hline & \multicolumn{2}{|c|}{ +Alta: 1.303.50 } & +Baixa: 1.064.50 & Média: 1.164.87 & Var\%: -10.66 \\
\hline
\end{tabular}

Fonte: Disponível em:http://br.investing.com/commodities/gold-historical-data. Acesso em: 21 nov. 2015.

Observa-se, por meio da Tabela 12, que é preciso aguardar o melhor momento para realizar a venda do ouro, pois a cada mês a ocorre variação, muitas vezes negativa em relação ao preço do produto pode diminuir o valor a ser recebido na venda. Mesmo que o investidor precise do dinheiro em 12 meses, deverá ter alguns dias, podendo ser em meses para encontrar a melhor oferta pelo preço do produto. A Tabela 12 possibilita observar que o ouro apresentou valores positivos durante seis dos 12 meses avaliados, sendo novembro de 2014 a outubro de 2015 . E por três meses consecutivos a cotação fechou em baixa, ou seja, o investidor precisaria esperar até quatro meses para vender com margem de lucro considerável e nove meses para obter a melhor cotação do ano de $7,99 \%$, em janeiro de 2015 . O risco médio do ouro está contido nesse aspecto, e pode eliminá-lo como opção de investimento em curto prazo, caso o investidor não disponha desse tempo para reaver o investimento (liquidez).

\section{CONSIDERAÇÕS FINAIS}

Esta pesquisa teve por objetivo geral analisar o impacto da tributação no resultado da rentabilidade dos principais investimentos e aplicações financeiras oferecidos no mercado financeiro nacional. Os resultados alcançados pelo primeiro objetivo específico de demonstrar a variação de rentabilidade obtida nos diferentes tipos de investimento do mercado financeiro nacional apontam que os rendimentos da VGBL de Renda Fixa, o CDB, LCI, LCA, Fundo de Investimento DI, e LTN Pré apresentam rendimentos superiores à poupança, variando de 9,45\% até $14,97 \%$. Mas, que os rendimentos mais significativos são o ouro e o dólar, que atingem margem de ganhos entre 44,02\% e 46,87\%, respectivamente, e o NTN-B (com ganho de $17,58 \%$ ). No entanto, aponta que para o dólar há risco alto, para o ouro risco médio e para o NTN-B risco baixo em relação ao investimento. Nesse contexto sugere avaliar outros indicadores capazes de influenciar na rentabilidade, como o Importo de Renda - IR e as taxas, além de determinar em que perfil o investidor se encaixa.

O segundo objetivo específico sendo em simular a variação de rentabilidade, no período de 12 meses, deduzindo a tributação aplicada aos diferentes tipos de investimentos e considerar sua influência no patrimônio total aponta para resultados que alteram o quadro alcançado pela análise do primeiro objetivo específico. Passam a ser investimentos de interesse para o valor de R \$ 100.000,00 no período de 12 meses as aplicações em: LTN Pré; LCA; LCI; NTN-B; ouro; e dólar. Ainda deve-se considerar que a poupança e as letras de câmbio (LCI e LCA) não possuem dedução de impostos e taxas administrativas. No entanto, a LCI e LCA só podem ser resgatados no dia do vencimento e o dinheiro não poderá ser movimentado durante o período e a poupança possui o menor rendimento entre os investimentos considerados. Os demais investimentos chegam a perder rendimentos entre 1,68\% (VGBL), até 7,05\% (no caso do dólar).

O terceiro objetivo específico do estudo de comparar os melhores resultados de rentabilidade aos riscos de cada um e à liquidez aponta que para o valor e o período, os riscos não devem ser altos, o rendimento deve ser o melhor possível e a liquidez também deve ser alta. Dessa forma, o dólar passa a ser desconsiderado como aplicação, a julgar o alto risco que apresenta. LCI e LCA possuem baixa liquidez e prazo determinado para movimento da aplicação, o que reduz sua validação como aplicação recomendada. Restam, então, três possibilidades: NTN, LTN e ouro. A alta liquidez e baixo risco do Tesouro Direto (NTN / LTN) são reduzidos em curto prazo pela baixa rentabilidade, que já está pré-estabelecida, mas para um 
retorno em longo prazo pode se apresentar como um fundo de renda fixa de rentabilidade média. O ouro, por conseguinte, apesar de oferecer médio risco, possui a mais alta rentabilidade e também apresenta alta liquidez, o que o torna o investimento mais indicado. A recomendação para o investimento é que o ganho pode ser maior caso o investidor possua tempo disponível para a venda, já que a análise do último ano para a aplicação evidencia até quatro meses consecutivos de cotação fechando em baixa. Mas, cujo ganho real pode se apresentar com até $25 \%$ de margem de lucro sobre o mais rentável dos investimentos de baixo risco.

No contexto geral, observa-se que o valor dos tributos pode alterar completamente o cenário ideal para o investimento. Infere-se que para fazer a melhor escolha é preciso avaliar o ganho real, o risco e a liquidez que o investidor terá, além de considerar o prazo de investimento e o perfil do investidor, que considera o nível de risco que está disposto a correr. A partir dos resultados, sugere-se que o investidor, antes de decidir-se por um ou outro investimento, seja orientado para a avaliação de todos os aspectos apontados e que as projeções para o futuro do investimento (pelo menos em curto prazo) seja também avaliado. Às organizações financeiras sugere-se apontar para o investidor, de forma simplificada e clara quais os investimentos se apresentam como melhores opções considerando-se o ganho real (sem IR e taxas), considerandose a liquidez e o risco, como uma forma de fidelizar o cliente. Nos dias atuais, segundo Schmitt (2004), a satisfação cria a fidelização do cliente.

\section{REFERÊNCIAS}

ASSAF NETO, Alexandre. Mercado financeiro. 12 ed. São Paulo: Atlas, 2014.

. Mercado financeiro. 7 ed. São Paulo: Atlas, 2006.

. Contribuição ao estudo da avaliação de empresas no Brasil: uma aplicação prática. 2004. Tese (Livre Docência). Faculdade de Economia, Administração e Contabilidade de Ribeirão Preto. Universidade de São Paulo: Ribeirão Preto, São Paulo, Brasil, 2004.

2014.

. LIMA, Fabiano Guasti. Curso de administração financeira. $3^{\mathrm{a}}$ ed. São Paulo: Atlas,

BACEN - Banco Central do Brasil. Taxas de câmbio. Disponível em: $<$ http://www4.bcb.gov.br/pec/taxas/port/ptaxnpesq.asp?id=txcotacao>. Acesso em: 03 nov. 2015.

BM\&FBOVESPA. O que são Debêntures. 2015. Disponível em: $<$ http://www.bmfbovespa.com.br/pt-br/renda-fixa/o-que-sao-debentures.aspx?idioma=ptbr>Acesso: 31 out. 2015.

BRASIL. Tesouro Direto. 2015. Disponível em: <http://www.tesouro.fazenda.gov.br/tesourodireto-conheca-o-tesouro-direto>. Acesso: 31 out. 2015.

Constituição da República Federativa do Brasil de 1988. Disponível em:

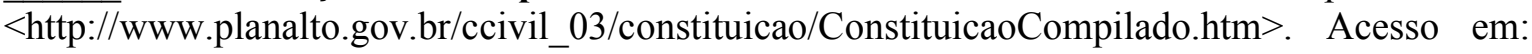
01 nov. 2015.

Banco Central do Brasil - BACEN. Composição e evolução do Sistema Financeiro Nacional (SFN). Disponível em: $<$ http://www.bcb.gov.br/?SFNCOMP $>$. Acesso em 01 nov. 2105. 
Receita Federal do Brasil. Dólar: ganho de capital. Disponível em: $<$ http://www.receita.fazenda.gov.br/PessoaFisica/IRPF/2015/perguntao/perguntas/pergunta600.html> . Acesso em 14 nov. 2105.

Resolução CMN 394, de 20 de outubro de 1976. O BANCO CENTRAL DO BRASIL, na forma do art. $9^{\circ}$ da Lei $\mathrm{n}^{\circ} 4.595$, de 31 de dezembro de 1964, torna público que o CONSELHO MONETÁRIO NACIONAL, em sessão realizada em 20 de outubro de 1976, tendo em vista o disposto no art. $4^{\circ}$, incisos VI, VIII, XI e XII, da referida Lei. 2015. Disponível em: $<$ http://www.bcb.gov.br/pre/normativos/res/1976/pdf/res_0394_v11_L.pdf> Acesso em: 04 nov. 2015.

Resolução CMN 52, de 20 de abril 1967. O BANCO CENTRAL DO BRASIL, na forma da deliberação do Conselho Monetário Nacional, em sessão de 20 de abril de 1967, face ao disposto no art. $1^{\circ}$ do Decreto-lei $\mathrm{n}^{\circ} 70$, de 21 de novembro de 1966 , e com fundamento no art. $9^{\circ}$, da Lei $\mathrm{n}^{\mathrm{o}} 4.595$, de 31 de dezembro de 1964. Disponível em: $<$ http://www.bcb.gov.br/pre/normativos/busca/downloadNormativo.asp?arquivo=/Lists/Normati vos/Attachments/40014/Res_0052_v1_O.pdf.>Acesso em: 04 nov. 2015.

CAMILO, C. C. Análise do perfil do investidor: um olhar dos condicionantes para os alunos de administração. UNIDESC - Centro Universitário de Desenvolvimento do Centro - Oeste. Goiás, 2012 .

CARNEIRO, R. Desenvolvimento em crise: a economia brasileira no último quarto do século XX. São Paulo: Editora UNESPE, IE - Unicamp, 2002.

CAVALCANTE, F; MISUMI, J. Y. Mercado de Capitais: o que é, como funciona. $7^{\text {a }}$ ed.Rio de Janeiro: Elsevier, 2009.

Rio de Janeiro: Elsevier, 2009.

; RUDGE. L. F. Mercado de capitais: o que é, como funciona. $7^{\text {a }}$ ed. rev. atual.

CNI - PEC.. Financiamento no Brasil: desafio ao crescimento. Brasília, D.F., CNI, 2003.

FACHIN, O. Fundamentos de metodologia. 4ª ed. São Paulo: Saraiva, 2003.

FOLHA DE SÃO PAULO. Entenda o que são risco, rentabilidade e liquidez de um investimento. São Paulo. Disponível em: <http://www1.folha.uol.com.br/mercado/767585entenda-a-diferenca-entre-os-investimentos-e-saiba-como-aplicar.shtml>. Acesso em: 04 nov. 2015.

HAIR JR., J. F. et al. Fundamentos de métodos de pesquisa em administração. Porto Alegre: Bookman, 2005.

INFOMONEY. LCI e LCA. 2015. Disponível em: <http://www.infomoney.com.br/lci-lca> Acesso em: 03 nov. 2015.

MEGLIORINI, E; VALLIM, M. A. R. S. Administração financeira: uma abordagem brasileira. São Paulo: Pearson Prentice Hall, 2009. 
MELLAGI FILHO, A.; ISHIKAWA, S. Mercado financeiro e de capitais. 2 ed. São Paulo: Atlas, 2014.

RIFFEL, Melanie Giacobbo. Crowdfunding: de modismo a novo instrumento financeiro. Dissertação (mestrado) - Escola Brasileira de Administração Pública e de Empresas, Centro de Formação Acadêmica e Pesquisa. Rio de Janeiro. 2016. 105 p.

SCHMITT, B. H. Gestão da experiência do cliente: uma revolução no relacionamento com os consumidores. Porto Alegre: Brookman, 2004.

SILVEIRA, C. M. (org.). Trabalho e renda: ações institucionais de fomento no Brasil. Rio de Janeiro: FASE/GTZ/NAPP/SACTES, 1995. 